\title{
Utility-Scale Wind and Solar in Emerging Markets- Private Sector Perspectives
}

\section{Global Context}

In 2018, nearly two trillion U.S. dollars were invested in the global energy sector, with clean energy investment totaling over \$332 billion (BNEF 2019) (IEA 2019). Despite a 1\% decrease from 2017, global investment in the power sector was once again larger than in the oil and gas sector for the third year in a row (IEA 2019). Forecasted to meet more than $70 \%$ of global electricity generation growth over the next five years, renewables are projected to have the fastest growth in the electricity sector, providing almost 30\% of power demand in 2023 (IEA 2018a).
In 2018, total global renewable energy capacity reached 2,351 gigawatts (GW), an increase of 7.9\% from 2017 (IRENA 2019). Solar and wind technologies continued to drive the increase in renewable generation capacity, accounting for $84 \%$ of new capacity (IRENA 2019). Solar was the top source of new power capacity in several major markets, with nonrenewable generation capacity decreasing in Europe, North America, and Oceania since 2010, with consistent reductions in capacity each year in Europe, and reductions in four of the last eight years in the other two regions (IRENA 2019). With sustained solar growth in the region, China, India,
Japan, and the Republic of Korea were the main contributors to the 64-GW increase in global solar capacity; China and the United States were the primary contributors to wind energy expansion.

Current trends in energy investment remain insufficient to meet projected energy needs (IEA 2018b). As policymakers and planners in emerging markets create enabling environments for clean energy investment to meet climate, air quality, energy access, and energy security goals, de-risking private sector investment will facilitate scaling up deployment of renewable energy and closing the investment gap.

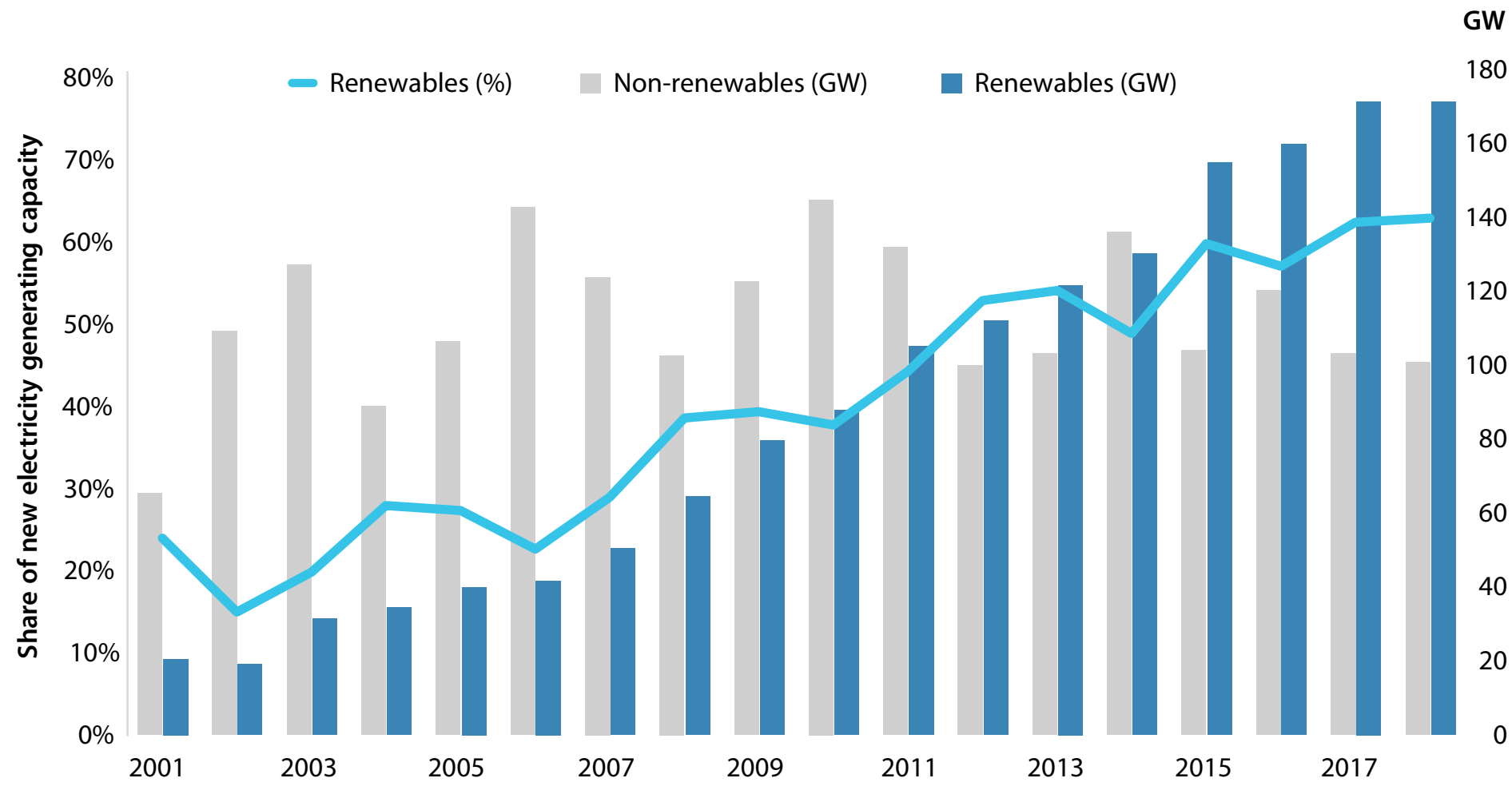

Figure 1: Renewable generation capacity and the energy transition. Adapted from: IRENA (2019) 


\section{Results and Key Barriers}

Despite the significant growth and investment in renewables, increased private sector investment will play a critical role in scaling up the deployment of clean energy technologies, particularly in emerging markets. While renewable energy market potential is high, private sector players face several barriers and uncertainties in nascent markets. Private sector representatives ranked various barriers to market entry in emerging markets, highlighting political instability, access to finance, lack of local technical expertise, and lack of renewable energy policies and incentives (including offtake risk, lack of technical and performance standards, and challenges in power grid access and the interconnection process) as their top barriers, seen in Figure 4.

This section presents an assessment of three commonly cited barriers and risks faced by private sector players in emerging renewable energy markets. The discussion provides a perspective for private sector needs, constraints, and insight on ways to strengthen the impact that enabling environment support and reform has on clean energy investment in developing countries. Political instability

\section{Methodology}

This paper is based on qualitative and quantitative data collection and analysis methods and provides an empirical understanding of barriers to private sector clean energy investment in emerging markets. Through literature review, a survey, and a series of webinar dialogues, USAID and the U.S. Department of Energy's (DOE's) National Renewable Energy Laboratory (NREL) solicited input from private sector actors, including developers, project financiers, manufacturers, and technical assistance service providers, on the challenges to market entry they face in emerging markets, as well as their suggestions for improving market competitiveness.

\section{Suzanne Leta, Global Market Strategy, SunPower}

"What we've seen that has been a bit more successful and has resulted in pricing environments that are both competitive and encourage projects that will actually come to fruition is more of an RFP-based approach, where you have a mix of requirements that result in a procurement, not just a price-based requirement. They are very focused on what the true levelized cost of energy is with the right production guarantees." ranked high as a barrier to market entry but is beyond the scope of this paper and will not be discussed.

Access to Finance: Mobilizing finance for clean energy investment and innovation can be challenging, especially early stage capital and finance (USAID-NREL 2018).

Access to funding for pre-investment due diligence, prefeasibility studies, and other such predevelopment costs associated with renewable energy development in emerging markets is critical in the early project development phase (IRENA 2016) (USAID-NREL 2018). Initial development costs can be a significant barrier, and supporting project pipeline development can help alleviate barriers and assist in facilitating renewable energy deployment in emerging markets (USAIDNREL 2018).

\section{Lack of Local Technical Expertise is} another notable barrier to private sector investment in emerging markets. A lack of technical expertise can result in several challenges, including delays in decision-making; local entities' inability to accurately assess competing projects on qualities other than projected costs; and a dearth of local, qualified laborers. Educating and providing technical assistance to decision makers and the local labor force on best practices could help build capacity and provide an opportunity to advance a deeper understanding of enabling operational strategies for advancing utility-scale renewable energy deployment (USAIDNREL 2018). Establishing systems that encourage cost-effective pricing, taking into consideration quality and probability of execution, can also support informed

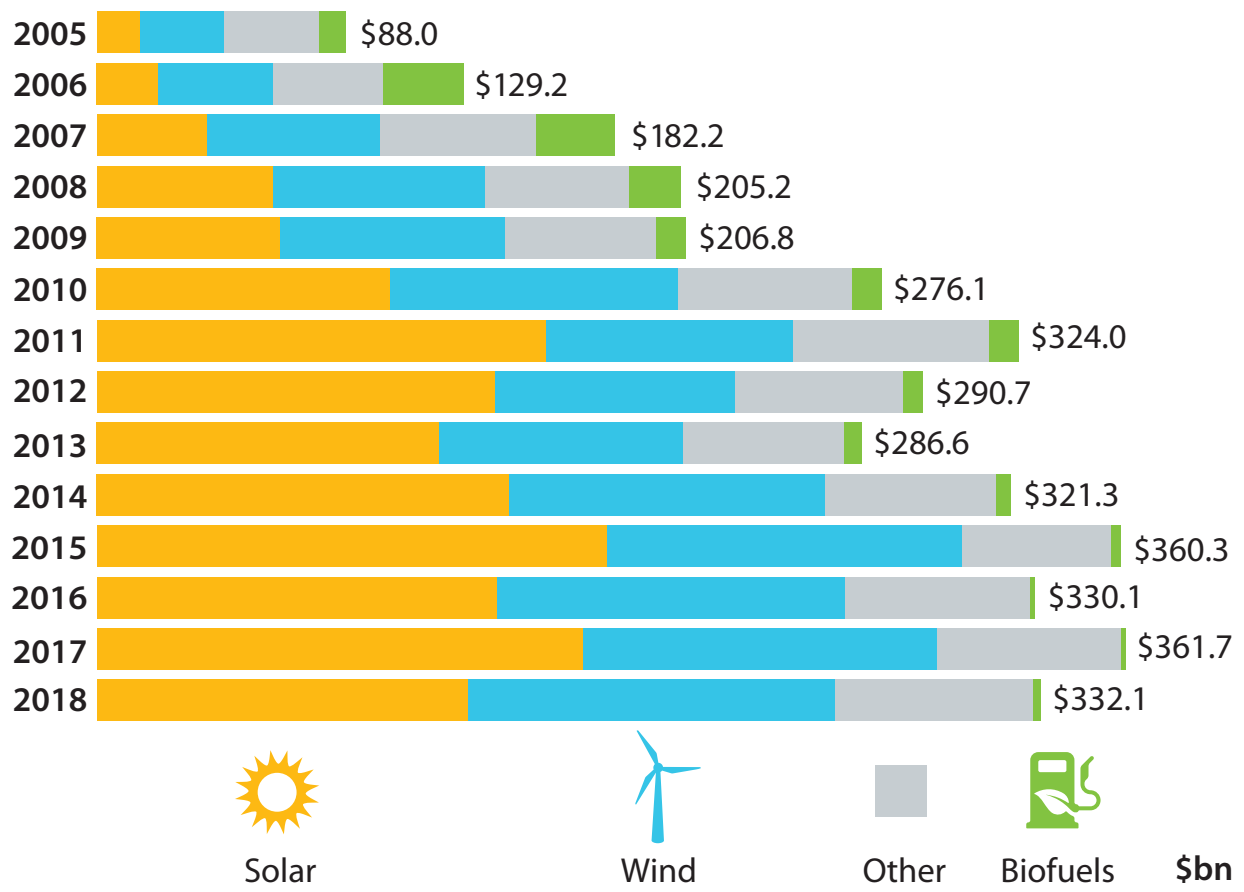

Figure 2: Global new investment in clean energy by sector. Adapted from: BNEF (2019) 

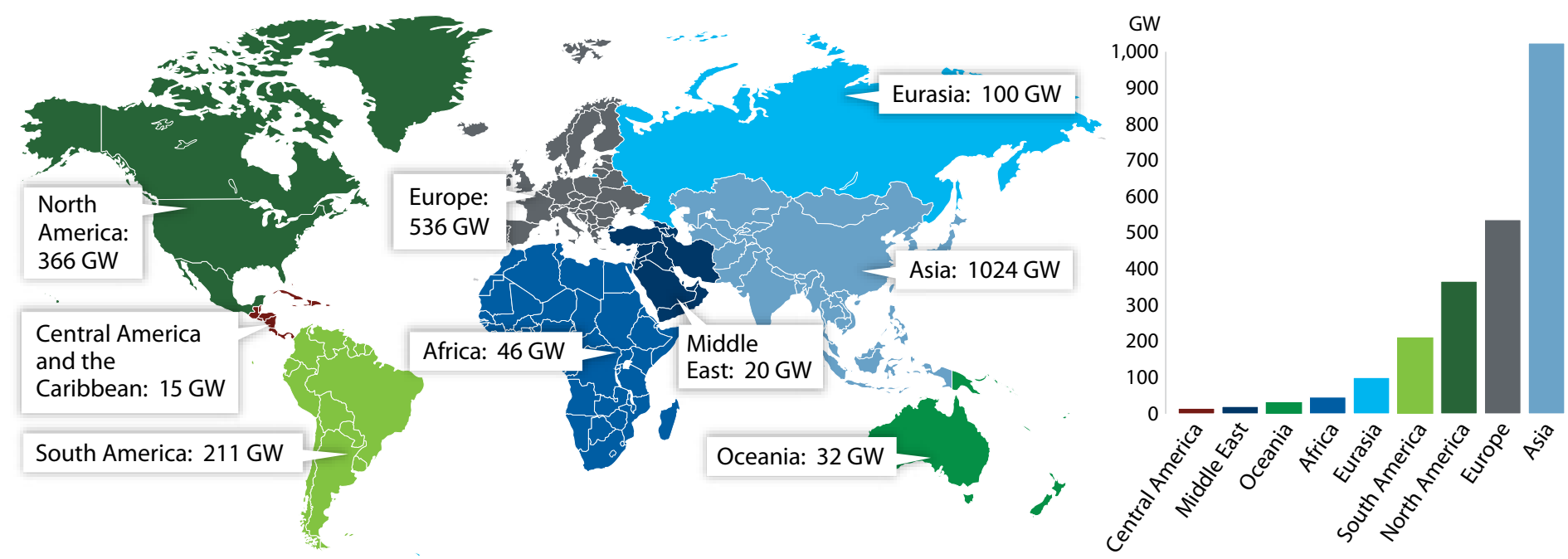

Figure 3: Renewable generation capacity at the regional level in 2018. Adapted from: IRENA (2019)

planning and investment in the clean energy sector (USAID-NREL 2018). For example, request for proposal (RFP) based approaches using internationally standardized templates and procedures can facilitate informed decision-making (USAID-NREL 2018). Similarly, supporting utilities in emerging markets to improve operations, decision-making processes, and understanding of renewable energy technologies can facilitate private sector investment (USAID-NREL 2018).

\section{Renewable Energy Policy and} Incentives: Providing a stable, transparent, and favorable policy environment supports reliable, long-term energy markets and catalyzing investment (IRENA 2014). Well-designed policies have been important to supporting investment in renewable energy over the past decade, and learning from past experiences and designing innovative policies are critical to tackling investment challenges (IRENA and CEM 2015).

Private sector players noted projects are often difficult to accurately budget or finish on schedule, due to a lack of technical and performance standards and enforced regulations (USAID-NREL 2018). For example, ill-defined interconnection standards present a potentially costly technical roadblock, impacting bottom-line considerations for private sector developers and investors.

\section{Possible Solutions}

Establishing stable and transparent policy and regulatory frameworks, strengthening technical capabilities, and improving access to early-stage finance could enable greater investment in utility-scale renewable energy projects. Supporting regulatory frameworks and improving the capacity of policymakers and planners to use analysis-based and data-driven decision-making can help to de-risking private sector investment in developing markets.

The following policy and technical support solutions could help remove barriers to private sector investment in emerging markets. These solutions could be implemented by policymakers or supported by members of the donor community:

- Establishing transparent interconnection standards that outline parameters, procedures, and timeline for grid connection;
- Developing template documents that meet international standards, including enforceable contracts, and welldesigned auctions and Power Purchase Agreements (PPA) that lower risk and facilitate high-quality competition and low prices in emerging markets;

- Strengthening technical capabilities for policymakers, utilities, regulators, laborers, and financial institutions to hasten and improve project development processes;

- Supporting pre-PPA due diligence and project development with access to grants and concessional loans;

- Ensuring investor confidence with government-backed sovereign guarantees specified in U.S. dollars;

- Promoting peer learning, sharing of best practices, modeling and software design support, study tours, and utility exchanges to learn from other utilities and decision makers.

\section{Dean Baumgardner, Partner and Chief Development Officer, Upepo Energy}

“We develop projects to meet lending standards and it doesn't really matter what procurement approach a country or utility is taking. We just want to know what approach is going to be used because we're confident that we could be competitive. If competitive bidding is used there needs to be a level playing field. We all need to work toward promoting fair and clear approaches to energy development." 
Reverse Auctions: A Policy

Tool to Accelerate Private Sector Engagement

Grid-connected renewable energy has seen an increased rate of adoption in Asia in the last five years, with several countries initiating competitive tenders and holding renewable energy reverse auctions. When implemented correctly, these procurement strategies can help accelerate private sector investment (including supply chain development), increase cost competitiveness, and spur large-scale renewable energy development.

The first renewable energy auctions in Kazakhstan were held in spring 2018. This landmark event represents the first time in the region local and international renewable energy developers were able to compete for rights to build large-scale clean energy projects in a transparent and competitive online bidding platform. The Renewable Energy Data Explorer provided an easy-to-use online platform for users to view, analyze, and download high-quality datasets for informed decision-making, including for structuring, developing, and running Kazakhstan's renewable energy auctions. According to Mr. Makhambet Dosmukhambetov, the First Vice Minister of Energy, the auctions attracted "competitive bids for a total capacity of 960 megawatts (MW)... which resulted in a $20 \%$ reduction of tariffs for wind power, a $25 \%$ reduction for solar power, and $23 \%$ reduction for small-hydro power stations."

\section{BARRIERS to market entry in emerging markets}

iin

Political

instability

Access to
finance
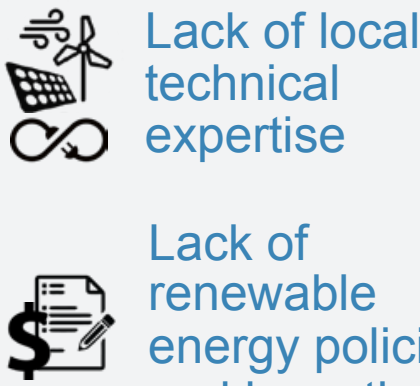

Lack of renewable energy policies and incentives

Figure 4: Top barriers to market entry in emerging markets based on feedback from private sector representatives

\section{Acknowledgements}

Jennifer Daw, Andrew Duvall, Philip Voris, NREL; Jennifer E. Leisch, Amanda Valenta, USAID; survey and webinar participants.

\section{References}

BNEF. 2019. "Clean Energy Investment and Trends, 2018." https://data.bloomberglp.com/professional/sites/24/BNEF-Clean-Energy-InvestmentTrends-2018.pdf.

IEA. 2018a. "Renewables 2018, Analysis and Forecasts to 2023." Paris, France: International Energy Agency (IEA). https://www.iea.org/ renewables2018/.

.2018b. "World Energy Outlook, 2018."

Paris, France: International Energy Agency (IEA). https://www.iea.org/weo2018/.

2019. "World Energy Investment

2019." Paris, France: International Energy Agency (IEA). https://webstore.iea.org/ world-energy-investment-2019.

IRENA. 2014. "Adapting Renewable Energy Policies To Dynamic Market Conditions." Abu Dhabi: International Renewable Energy Agency (IRENA). https://www.irena.org/publications/2014/ May/Adapting-Renewable-Energy-Policies-ToDynamic-Market-Conditions.

____. 2016. “Unlocking Renewable Energy Investment: The Role of Risk Mitigation and Structured Finance." Abu Dhabi: International Renewable Energy Agency (IRENA). https://www. irena.org/publications/2016/Jun/UnlockingRenewable-Energy-Investment-The-role-of-riskmitigation-and-structured-finance.

\section{___ 2019. "Renewable Capacity}

Statistics 2019." Abu Dhabi: International Renewable Energy Agency (IRENA). https:// www.irena.org/publications/2019/Mar/ Renewable-Capacity-Statistics-2019.

IRENA, and CEM. 2015. "Renewable Energy Auctions: A Guide to Design." Abu Dhabi: International Renewable Energy Agency (IRENA) and Clean Energy Ministerial (CEM). https:// www.irena.org/publications/2015/Jun/ Renewable-Energy-Auctions-A-Guide-to-Design.

USAID-NREL. 2018. Utility-Scale Wind and Solar in Emerging Markets: Understanding the Barriers to Private Sector Engagement in the Energy Sector Webinar Series. https://www.usaid.gov/ energy/private-sector-engagement-webinars/ wind-solar.

Written by Carishma Gokhale-Welch and Andrea Watson, National Renewable Energy Laboratory

www.nrel.gov/usaid-partnership

Jennifer E. Leisch, Ph.D.

USAID-NREL Partnership Manager

U.S. Agency for International Development

Tel: +1-303-913-0103 | Email: jleisch@usaid.gov

\section{Andrea Watson}

USAID Portfolio Manager

National Renewable Energy Laboratory

Tel: +1-303-275-4234 | Email: andrea.watson@nrel.gov

This work was authored, in part, by the National Renewable Energy Laboratory (NREL), operated by Alliance for Sustainable Energy, LLC, for the U.S. Department of Energy (DOE) under Contract No. DE-AC36-08GO28308. Funding provided by the United States Agency for International Development (USAID) under Contract No. IAG-17-2050. The views expressed in this report do not necessarily represent the views of the DOE or the U.S. Government, or any agency thereof, including USAID.

NREL/TP-7A40-74154 | June 2019

NREL prints on paper that contains recycled content.
The USAID-NREL Partnership addresses critical challenges to scaling up advanced energy systems through global tools and technical assistance, including the Renewable Energy Data Explorer, Greening the Grid, the International Jobs and Economic Development Impacts tool, and the Resilient Energy Platform. More information can be found at: www.nrel.gov/usaid-partnership. 